\title{
Behandling for kronisk utmattingssyndrom
}

Kronisk utmattingssyndrom (chronic fatigue syndrome) er ein sjukdomstilstand som har skapt interesse og strid i lang tid. Sjukdomsforståing, klassifikasjon og etiologi har vore omstridd, og kunnskap om behandlingseffekt har vore liten. Inntil nyleg har tilstanden vore rekna som vanskeleg å lækje, knapt nok lindre. Kvilekur på sanatorier var tidlegare vanleg behandling, og kvileterapi blir framleis ofte tilrådd, sjølv om forsking ikkje kan vise effekt av dette (1). Systematiske forskingsoversiktar har vist at effekten av behandlingstiltak ved kronisk utmattingssyndrom er svært varierande, og at det enno ikkje er dokumentert at ein spesifikk behandlingsmetode er effektiv for alle pasientar (2). Likevel er det nokre funn som synest konsistente. Det gjeld særleg kognitiv åtferdsterapi, som viser god effekt på dei fleste resultatmåla ved systematisk intervensjon $(2,3)$. Også fysisk aktivitet og gradert treningsterapi er vist å ha positiv effekt ved kronisk utmattingssyndrom, sjølv om det her er ujamne funn (4).

I ein rapport frå Nasjonalt kunnskapssenter for helsetjenesten (5) har ein evaluert alle studiar med kvalitet etter krav til kunnskapsbasert medisin. Hovudkonklusjonen er at kognitiv åtferdsterapi og gradert treningsterapi har vist systematisk effekt. Likevel er det usemje om desse funna verkeleg representerer sann kunnskap om behandlingseffekt. Særleg har pasientorganisasjonar vore kritiske til om desse funna er gyldige, både pga. pasientseleksjon (det er sjeldan at pasientar med dei mest alvorlege plagene, sengeleie og omfattande funksjonssvikt er inkluderte, fordi dei har praktiske vanskar med å delta), ujamn bruk av resultatmål og tolking av resultatdata. Pasientorganisasjonane refererer til den erfaringskunnskapen som deira pasientar har, som ikkje stemmer med dei ovannemnde resultata.

Det er viktig å ta desse innvendingane på alvor, ikkje minst fordi god forsking er avhengig av kritisk argumentasjon, av røynsler som kan utfordre og av at ein lar seg utfordre. I ein artikkel i dette nummer av Tidsskriftet (6) blir det presentert ein studie med bakgrunn i pasientar sine eigne røynsler med nytte av kognitiv åtferdsterapi, gradert treningsterapi og individuell aktivitetsregulering (pacing - der ein tilpassar aktivitet til dagsform og opplevd energi). Konklusjonen i denne studien er at dei fleste pasientar meiner at aktivitetsregulering er den beste behandlinga og at røynsler med kognitiv åtferdsterapi er moderat gode og med gradert treningsterapi oftast negative.

Det er vanskeleg å vite kor representative slike syn og røynsler er kven og kor mange har faktisk røynsle med systematisk behandling. Og er det slik at dei som svarer, representerer den typiske pasienten med kronisk utmattingssyndrom? Studiar har vist at pasientorganisasjonar ofte gjev uttrykk for kritiske syn på kognitiv åtferdsterapi og gradert treningsterapi, og at kritiske meiningar er mest utbreidd blant aktive medlemmer (7). Det er ei vanleg oppfatning i denne gruppa at individuell aktivitetsregulering (pacing) er den beste behandlingsforma ved kronisk utmattingssyndrom, utan at det finst særleg forsking på dette. Det pågår ein stor multisenterstudie i England der ein systematisk vil granske effekten av pacing ved kronisk utmattingssyndrom (8).

I den aktuelle studien er det berre medlemmer av pasientorganisasjonane for kronisk utmattingssyndrom som er spurde, og svar- prosenten er låg. Kvaliteten i dei behandlingstilboda som blir refererte til, er ikkje kjent. Ein kan difor stille spørsmål ved kor representativt utvalet av respondentar er, og dermed kor gyldige konklusjonane er. Blant medlemmer i støttegrupper blir det uttrykt meir negative syn på denne type behandling enn i pasientgruppa generelt, noko som kan tenkjast å influere på responsen, og denne gruppa synest også å ha mindre effekt av slik behandling enn andre pasientar $(7,9)$. Den føreliggjande studien kan indikere kva ein del av medlemmene i pasientorganisasjonar meiner, men den kan ikkje gje svar på om dette gjeld generelt for pasientar med kronisk utmattingssyndrom, eller kva effekt behandlingsintervensjon etter kunnskapsbaserte retningslinjer kan ha.

I det vidare arbeidet for å auke kunnskapen om kronisk utmattingssyndrom er det viktig å ta imot og gjere nytte av brukarrøynsler, ikkje minst frå dei aller sjukaste, og integrere dette med kunnskapsbasert medisin og god kvalitet i kunnskapsutvikling. Klinisk forsking må omfatte brukarrøynsle, og brukarrøynslene må kunne vurderast like nøye som andre data og informasjonskjelder. Det er gjort lite forsking på kronisk utmattingssyndrom i landet vårt, og all ny kunnskap kan vere nyttig for å auke forståing av kronisk utmattingssyndrom og for å utvikle gode behandlingstilbod.

\section{Bjarte Stubhaug \\ bjarte@stubhaug.no}

Bjarte Stubhaug (f.1956 ) er førsteamanuensis dr.med. ved det Medisinsk-odontologiske fakultet, Universitetet i Bergen og fagleg ansvarleg ved Frihamnsenteret, Skånevik.

\section{Oppgitte interessekonflikter: Ingen}

\section{Litteratur}

1. Sharpe M, Wessely S. Putting the rest cure to rest - again. BMJ 1998; 316: 796 .

2. Chambers D, Bagnall AM, Hempel S et al. Interventions for the treatment, management and rehabilitation of patients with chronic fatigue syndrome/ myalgic encephalomyelitis: an updated systematic review. J R Soc Med 2006; 99: $506-20$.

3. Price JR, Mitchell E, Tidy E et al. Cognitive behaviour therapy for chronic fatigue syndrome in adults (Review). Cochrane Database Syst Rev 2000; nr. 3: CD001027.

4. Edmonds M, McGuire H, Price J. Exercise therapy for chronic fatigue syndrome. Cochrane Database Syst Rev 2004: nr. 3: CD003200.

5. Wyller VB, Bjørneklett A, Brubakk $O$ et al. Diagnostisering og behandling av kronisk utmattelsessyndrom/myalgisk encefalopati (CFS/ME). Rapport nr. 9/2006. Oslo: Nasjonalt kunnskapssenter for helsetjenesten, Sosial- og helsedirektoratet, 2006.

6. Bjørkum T, Wang CE, Waterloo K. Pasienterfaringer med ulike tiltak ved kronisk utmattelsessyndrom. Tidsskr Nor Legeforen 2009; 129: 1214-6.

7. Friedberg F, Leung DW, Quick J. Do support groups help people with chronic fatigue syndrome and fibromyalgia? A comparison of active and inactive members. J Rheumatol 2005: 32: 2416-20.

8. White PD, Sharpe MC, Chalder T et al. Protocol for the PACE trial: a randomised controlled trial of adaptive pacing, cognitive behaviour therapy, and graded exercise, as supplements to standardised specialist medical care versus standardised specialist medical care alone for patients with the chronic fatigue syndrome/myalgic encephalomyelitis or encephalopathy. BMC Neurol 2007: 7: 6 .

9. Bentall RP, Powell P, Nye FJ et al. Predictors of response to treatment for chronic fatigue syndrome. Br Journal Psychiatry 2002; 181: 248-52. 